\title{
Low recovery of bacterial community after an extreme salinization-desalinization cycle

Yang $\mathrm{Hu}^{1,2}$, Chengrong Bai ${ }^{1,2}$, Jian Cai ${ }^{1,2}$, Keqiang Shao ${ }^{1}$, Xiangming Tang ${ }^{1}$ and Guang Gao ${ }^{1 *}$

\begin{abstract}
Background: Understanding the recovery of bacterial communities after extreme environmental disturbances offers key opportunities to investigate ecosystem resilience. However, it is not yet clear whether bacterial communities can rebound to their pre-disturbance levels. To shed light on this issue, we tracked the responses of bacterial communities during an extreme salinization-desalinization cycle.

Results: Our results showed that salinization-up process induced an ecological succession, shifting from a community dominated by Betaproteobacteria to Gammaproteobacteria. Within the desalinization-down process, taxon-specific recovery trajectories varied profoundly, with only Gammaproteobacteria returning to their initial levels, of which Alphaproteobacteria was the most prominent member. The a-diversity indices gradually increased at oligosaline environment $(0.03 \%$ to $3 \%)$ and subsequently decreased profoundly at hypersaline condition (10\%o to $90 \%)$ ). However, the indices did not return to pre-disturbance level along the previous trajectory observed during the desalinization. Approximately half of the original OTUs were not detected during desalinization, suggesting that the seed bank may be damaged by the hypersaline environment. Moreover, Phylogenetic Investigation of Communities by Reconstruction of Unobserved States (PICRUSt) implied that the osmosensors' capacity of bacterial communities was also impaired by the hypersaline condition.
\end{abstract}

Conclusions: These results suggested that the bacterial communities showed a low recovery after the extreme salinization-desalinization cycle.

Keywords: Bacterial community, Salinization-desalinization cycle, Recovery, Seed bank, Osmosensor capacity

\section{Background}

Disturbance, defined as an event that triggers the environmental change, has lasting (positive or negative) influences on every level of biological organization at a broad range of spatio-temporal scales. Following from previous studies, it has been established that disturbance displaces or damages individuals to create opportunity for new individuals to establish themselves, leading to community succession $[1,2]$. A series of concepts have been proposed to elucidate the community patterns associated with disturbance, including stability, resilience, and variability [3-5]. Inherently, disturbance is diverse with respect to either endogenous and exogenous or either natural and anthropogenic origins. Thus, the

\footnotetext{
* Correspondence: niglas@gmail.com

${ }^{1}$ State Key Laboratory of Lake Science and Environment, Nanjing Institute of Geography and Limnology, Chinese Academy of Sciences, 73 East Beijing Road, Nanjing 210008, China

Full list of author information is available at the end of the article
}

community responses to disturbance are also correspondingly diverse [6-8]. However, despite of these rich responses, little is known within the context of community robustness that whether community can recover to its pre-disturbance level after the disturbance [9-11].

Microbes are the major contributors for ecosystem functions, playing an essential role in organic matter mineralization, nutrient regeneration, and energy flow $[12,13]$. Thus, the robustness of microbial communities to a disturbance is essential for understanding the ecosystem stability. On one hand, some ecological theories (e.g. niche theory and species-sorting process), which are characterized by deterministic mechanisms, potentially argue that the microbial community will eventually rebound to its initial level after a disturbance $[14,15]$. For instance, aquatic bacterial communities generally matched their initial composition by the 10th day after lake mixing [11]. Similarly, bacterial diversity is also comparable with its initial levels on day 
5 after a heavy Microcystis bloom [16]. These results suggest that there is only one fate for a bacterial community in a given environment. However, modern ecology has recently begun to challenge these dogmas. The failure or incomplete recovery of a bacterial community has been repeatedly recorded after specific disturbances, such as frequent antibiotic perturbation [10] and violent wind-disturbance [17]. Advocators challenging a single-fate model claim that the succession trajectory of a microbial community is not only controlled by deterministic mechanisms, but is also subjected to stochastic processes, such as dispersal limitation, priority effect, and ecological drift [18-21]. Thus it is expected that there would be multiple end-states for bacterial communities in a given environment $[7,22]$. As a consequence, the microbial community may not rebound to its pre-disturbance level. Given these two contrary arguments, it is crucial to provide new insights into bacterial community recovery in order to better understanding the ecology of disturbance.

As one of the most influential factors, salinization is a heavy disturbance to bacterial communities and defines the distribution of a bacterial community in various habitats $[23,24]$. At the individual level, salinization threatens the bacterial species with a drastic loss of water due to high osmotic pressure [25], leading to specific functions being largely inhibited, such as respiration [26] and nitrification [27]. At the community level, salinization induces an ecological succession, moving from a community dominated by halosensitive to halotolerant species [28-30]. For instance, Betaproteobacteria, the most prominent group in freshwater, is gradually displaced by Gammaproteobacteria along a saline gradient [31-34]. Notably, salinity is not always constant but fluctuates over time in natural ecosystems. In this case, the bacterial community is expected to not only suffer from salinization, but also from subsequent desalinization [35]. Although desalinization causes a symmetric change in osmotic pressure relative to salinization, there is a knowledge gap surrounding whether the bacterial community is able to recover its pre-disturbance level after desalinization. Therefore, the salinization-desalinization cycle provides a unique model for to understanding the robustness of bacterial communities.

To offer insights into the recovery of a microbial community, we performed a mesocosm experiment to investigate responses to the salinization-desalinization cycle. Specifically, the microbial community is manipulated to through six salinity levels from freshwater to extreme saline water $(0.03 \%, 1 \%, 3 \%, 10 \%$, $35 \%$, and $90 \%$ ), and then returning in reverse fashion to freshwater $(90 \%$, $35 \%$, $10 \%$, 3\%, $1 \%$, and $0.03 \%$ ). The selection criteria for the salinity levels is based on natural salinity ranging from $0.03 \%$ (freshwater) to $35 \%$ (ocean water), and even up to $90 \%$ (hypersaline water) [36, 37]. Although there is an inverse relationship between disturbances frequency and magnitude (large disturbance seldom occurs, while small disturbance occurs frequently), disturbance of extreme salinity is inherently difficult to study in nature. However, the responses of a microbial community after extreme salinity are essential to understanding their recovery ecology $[38,39]$. By investigating how bacterial community might responds to a salinization-desalinization cycle, we attempt to describe the microbial community's ability to recover to its pre-disturbance levels.

\section{Results}

Physicochemical characteristics during the experiment

The major physicochemical characteristics of experimental water were tracked (Additional file 1: Table S1). In the control group, all environmental properties showed minor variation, indicating the steady state of the system during the experiment. Within the treatment group, only the salinity increased from freshwater $(0.03 \%)$ to the hypersaline condition $(90 \%)$, and then symmetrically recovered to freshwater $(0.03 \%$ ) as described. Other major environmental factors showed no significant variation during the experimental period.

\section{The overall bacterial community diversity during salinization-desalinization cycle}

We selected the universal forward primer $798 \mathrm{~F}$ and reverse primer $1068 \mathrm{R}$ to amplify bacteria and archaea. The coverage of bacteria was $98.0 \%$ for both forward and reverse primer, while that of archaea was 96.6 and 99.2\%, respectively (https://www.arb-silva.de/). However, the Illumina sequencing results showed that only 5 OTUs belonging to archaeal group were detected, which accounted for $<1 \%$ within the prokaryotic community. This finding suggested the archaeal community was particular rare relative to bacterial community. Based on the archaeal rarity, we only focused on the recovery of bacterial community during the salinization-desalinization cycle.

Our sequence-processing strategy yielded an average of 97,143 raw reads from each sample with a length of approximately $225 \mathrm{bp}$. After trimming, screening and removing chimeras, 67,309 high quality sequences for each sample were obtained, which were clustered into 2,418 OTUs across all 22 samples. Rarefaction curves of OTUs were used to estimate bacterial diversity among the salinization-desalinization cycle (Additional file 2: Figure S1). All rarefaction curves reached a plateau indicating that the sequencing depth has been guaranteed. Also, the high Good's coverage (from 99.03 to $99.61 \%$ ) supported the sufficient sequencing effort.

To characterize bacterial community robustness, we analyzed $\alpha$-diversity patterns during the salinization- 
desalinization cycle (Fig. 1). In the control group, all diversity indices fluctuated and undulated slightly through whole experimental period. During the salinization-up process, our results showed two contrary trends of bacterial diversity. Specifically, all diversity indices increased at salinity from $0.03 \%$ o to $3 \%$, whereas they drastically dropped at salinity from $10 \%$ to $90 \%$. Thus, there were two salinity spectrums for bacterial communities during the salinization process: oligosaline environment (from $0.03 \%$ to $3 \%$ ) and hypersaline environment (from $10 \%$ to $90 \%$ ). Within the subsequent desalinization-down process, although Shannon and Pielou indices showed an acute increase, values were still significantly lower than the control group $(t$-test, $P<0.001)$. Phylogenetic diversity and the number of OTUs were also not comparable with the control group $(t$-test, $P<0.001)$. Thus, diversity observations indicate that the bacterial communities did not recover to pre-disturbance levels after an extreme salinization-desalinization cycle. In order to explore the persistence, appearance and loss of OTUs within the salinization-desalinization cycle, we assigned OTUs that were detected in the control group to original OTUs and assigned OTUs that only appeared in the treatment group to unique OTUs (Fig. 2). The original OTUs continuously dropped steadily from 89.38 to $50.46 \%$ within salinizationup process and oscillated around $55.80 \%$ within the desalinization-down process. Consistently, the loss of OTUs increased gradually within the salinization and maintained a constant presence during desalinization. By contrast, there is an acute increase in the unique OTUs at salinity from $0.03 \%$ to $3 \%$.

We next assessed the $\beta$-diversity of bacterial communities during the salinization-desalinization cycle.
With NMDS based on the Bray-Curtis similarities, salinization-up process clearly induced an ecological community succession, which deviated from that observed in the control group (Fig. 3). Analyses using the (un)weighted UniFrac method also provided similar results (Additional file 3: Figure S2). The PERMA NOVA test also indicated that salinization communities were significantly different from the control group $(P<0.01)$. Of particular interest, salinization communities experienced an acute change between $3 \%$ and $10 \%$. And bacterial communities were significantly different between from $0.03 \%$ to $3 \%$ as well as from $10 \%$ to $90 \%$ o $(P<0.05)$. This finding again implied that there were two salinity spectrums for bacterial communities: oligosaline and hypersaline environments. Strikingly, the desalinization communities did not rebound to pre-disturbance levels along their previous trajectories (Fig. 3). During the desalinization process, variability was evident, but was constrained around an average community composition that was generally stable. The communities were still visualized closer to the hypersaline community but significantly differed from their original control group $(P<0.01)$. Taken together, these observations may suggest an incomplete recovery of bacterial communities after an extreme salinization-desalinization cycle.

\section{Bacterial community profiles during the salinization- desalinization cycle}

Within the control community, a total of 18 phyla were detected in all samples, with the top 3 accounting for approximately $86.5 \%$ of the whole community. Specifically, Proteobacteria (69.23\%) was the most abundant phylum

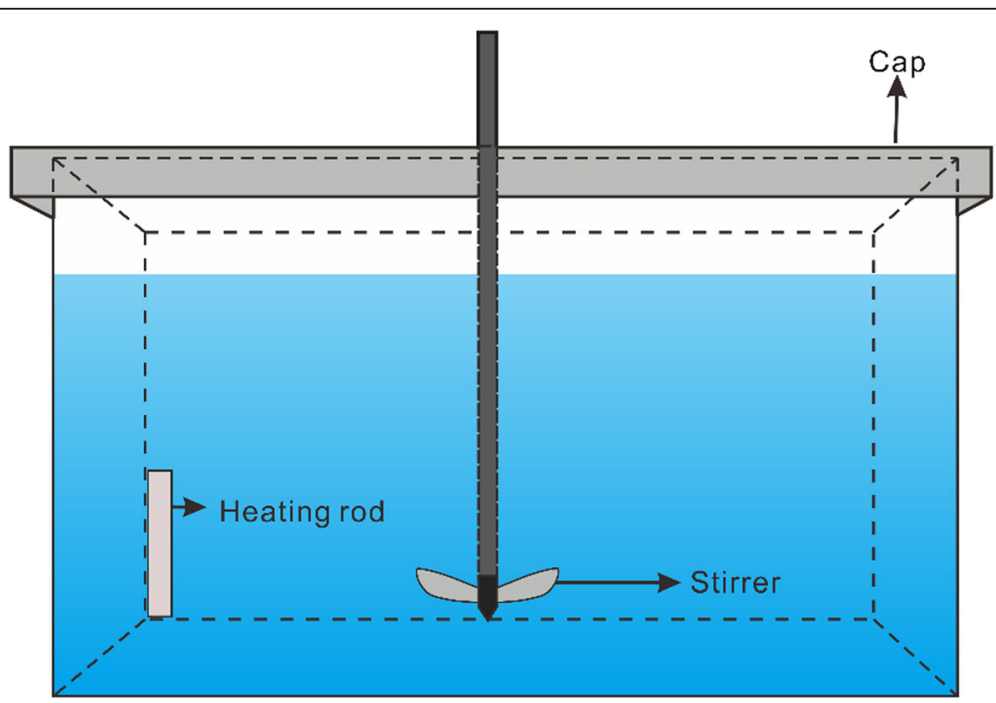

Fig. 1 The a-diversity of bacterial communities of control and treatment groups based on Shannon index, Pielou index, Phylogenetic diversity and number of OTUs. The horizontal axis represents the status of salinity, S represents salinization, D represents desalinization, and the numbers after each letter represents the salinity in parts per thousand 


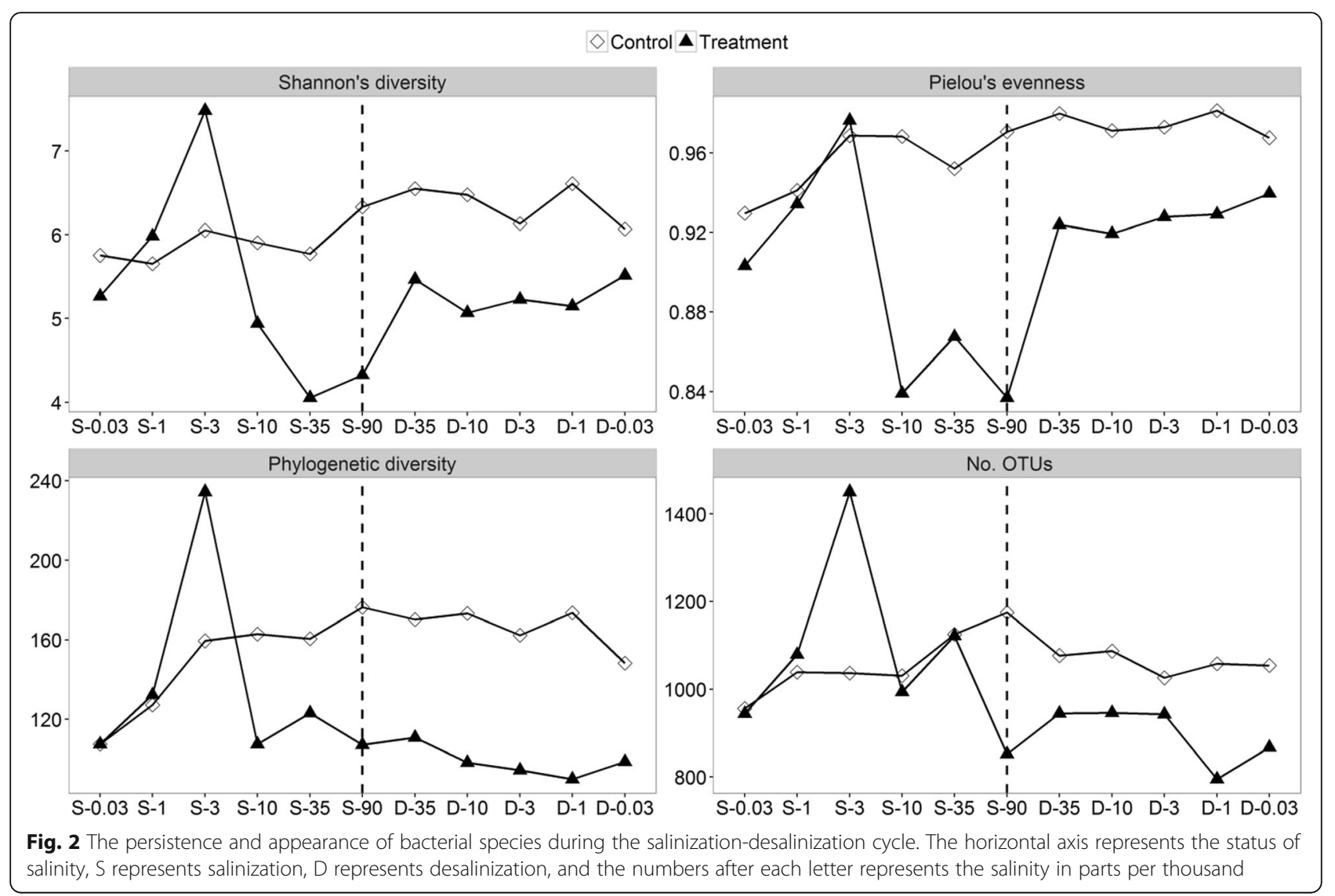

in all samples, followed by Bacteroidetes (12.31\%) and Verrucomicrobia (11.28\%). Further analysis at lower taxonomic level showed that prominent classes consisted of Betaproteobacteria (49.21\%), Alphaproteobacteria (9.04\%), and Gammaproteobacteria (3.24\%). The presence of all phylotypes was fairly constant during the experimental period (Additional file 4: Figure S3).

There were distinct responses to the salinizationdesalinization cycle among phylogenetically coherent groups at the class level (Fig. 4). During the salinization-up process, Betaproteobacteria maintained their dominance at salinity up to $1 \%$, accounting for $65.28 \%$. However, their proportion drastically declined to $0.04 \%$ at salinity of $3 \%$, even decreased to $0.02 \%$ at the hypersaline environmental range (from $10 \%$ to $90 \%$ ). Alphaproteobacteria and Planctomycetacia both increased at the oligosaline condition. However, Alphaproteobacteria oscillated around 19.00\% at the hypersaline environment, whereas Planctomycetacia largely declined to $1.64 \%$. By contrast, Gammaproteobacteria continuously increased during the salinization and bloomed to become the most prominent group at salinity of $90 \%$.

Taxon-specific recovery trajectories varied markedly during the desalinization-down process. Betaproteobacteria increased from 4.40 to $12.55 \%$ with the decreasing salinity. However, their recovered proportion was still not comparable with their initial level. Instead, Alphaproteobacteria continued to increase to $50.42 \%$ as the most prominent member after the desalinization. Similarly, Sphingobacteria also exhibited an increase to around $19.26 \%$, which was significantly higher than their original proportion (2.35\%). Strikingly, only Gammaproteobacteria showed a symmetric pattern during the salinization-desalinization cycle, decreasing from 71.89 to $9.27 \%$. Together, the shifts of these members implied that bacterial community composition did not recover to the initial level after the disturbance.

\section{Predictive metagenome analysis}

We used the PICRUSt program to predict metagenome functional content based on the KEGG classification. The nearest sequenced taxon index (NSTI) was employed to quantify the availability of nearby genome representatives for each sample (Additional file 5: Table S2). We mainly focused on five pathways (as defined by KEGG above) during the salinization-desalinization cycle: DNA repair and recombination proteins, DNA replication proteins, MAPK signaling pathway-yeast, inorganic ion transport, and two-component system (Fig. 5). All these pathways are involved in osmotic regulation. There were no significant differences in these 


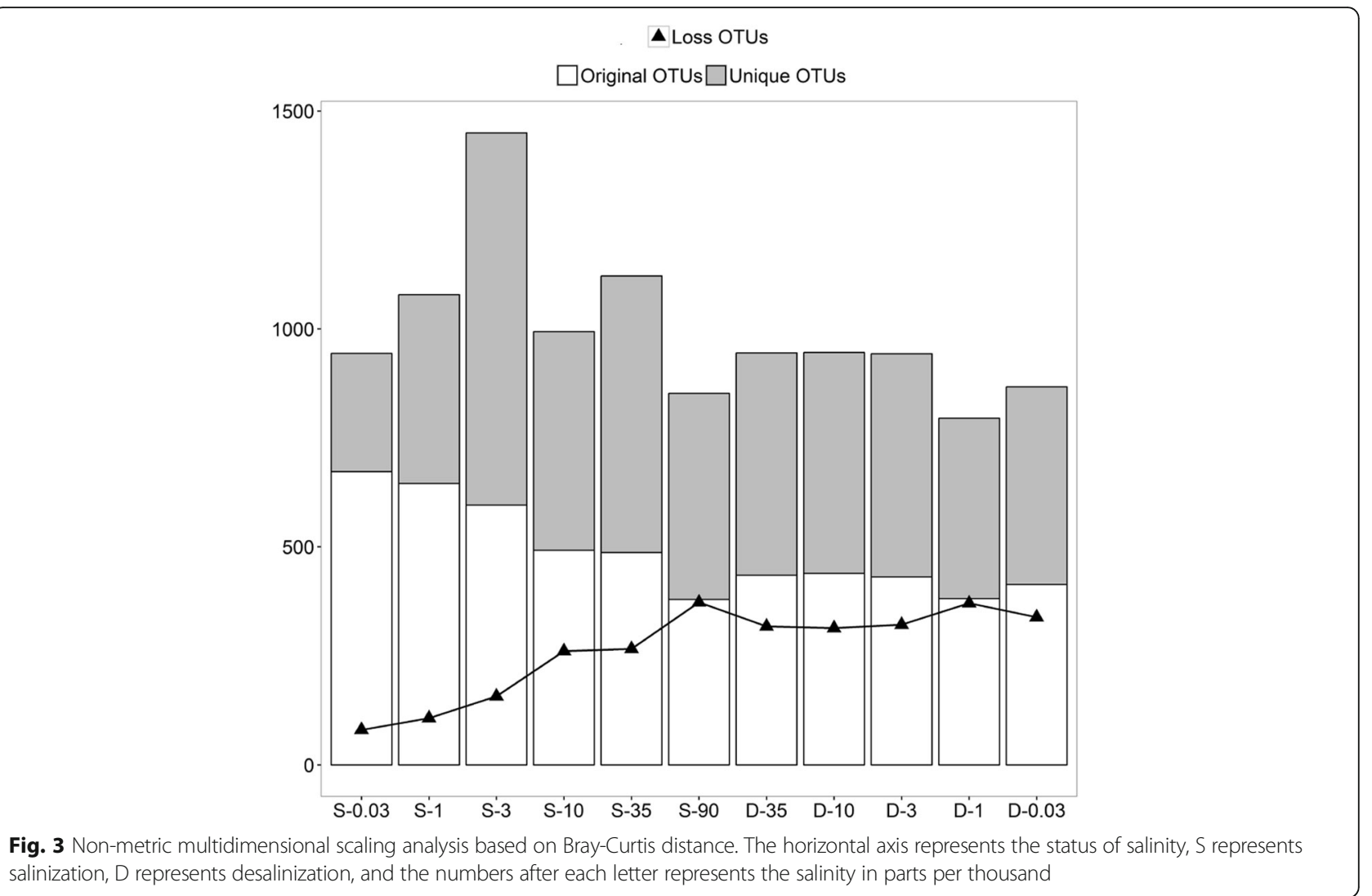

pathways between the control groups and the oligosaline condition (all $P>0.05$ ). As the salinity continuously increased to hypersaline condition they were all significantly depleted from the oligosaline to hypersaline environment (all $P<0.05$ ). However, they did not clearly increase as the salinity decreased (all $P>0.05$ ). None of these five osmotic regulation pathways rebounded to their previous levels in freshwater controls.

\section{Discussion}

Over the last few decades, significant progress has been achieved in bacterial community ecology, however, characterizations of their recovery from disturbance are still largely unexplored. This is mainly because few studies follow bacterial communities over the time-course, but instead focus on the community sensitivity or immediate responses to disturbance $[11,40]$. To address whether the bacterial community can recover to its initial state after a large disturbance, the current study artificially manipulated the bacterial community to through an extreme salinization-desalinization cycle. Our results showed that salinization-up process strongly induced an ecological succession in the bacterial community, however, the community did not recover to its pre-disturbance level along the previous trajectory during desalinization-down process.

The results of this study highlight that the bacterial community became richer within the increasing salinity range from $0.03 \%$ to $3 \%$. As has been stated above, salinity generally threatens the cell with a drastic loss of water due to higher osmotic pressure. Thus, it is widely held that there is a decrease in diversity for biota, particularly for floral and faunal species [41, 42]. However, this pattern seems to be less reproducible for bacterial communities. Relevant work has recorded that the bacterial taxon richness increased with increasing salinity up to a value of $1 \%$ [36]. A similar study also observed no significant decrease in bacterial diversity until salinity was $6.86 \%$ [31]. As the typical freshwater group, Betaproteobacteria maintained their dominance at salinity from $0.03 \%$ to $3 \%$, with a relative abundance of $66.15 \%$. Concurrently, Alphaproteobacteria and Gammaproteobacteria, which are represented in saltwater habitats, clearly increased in the oligosaline condition. Therefore, the salinity-diversity pattern of bacterial communities may be related to the greater niche availability for both halotolerant and halosensitive bacteria at a moderate salinity level $[34,36]$.

Subsequent to experiencing oligosaline conditions, bacterial community diversity declined sharply at 


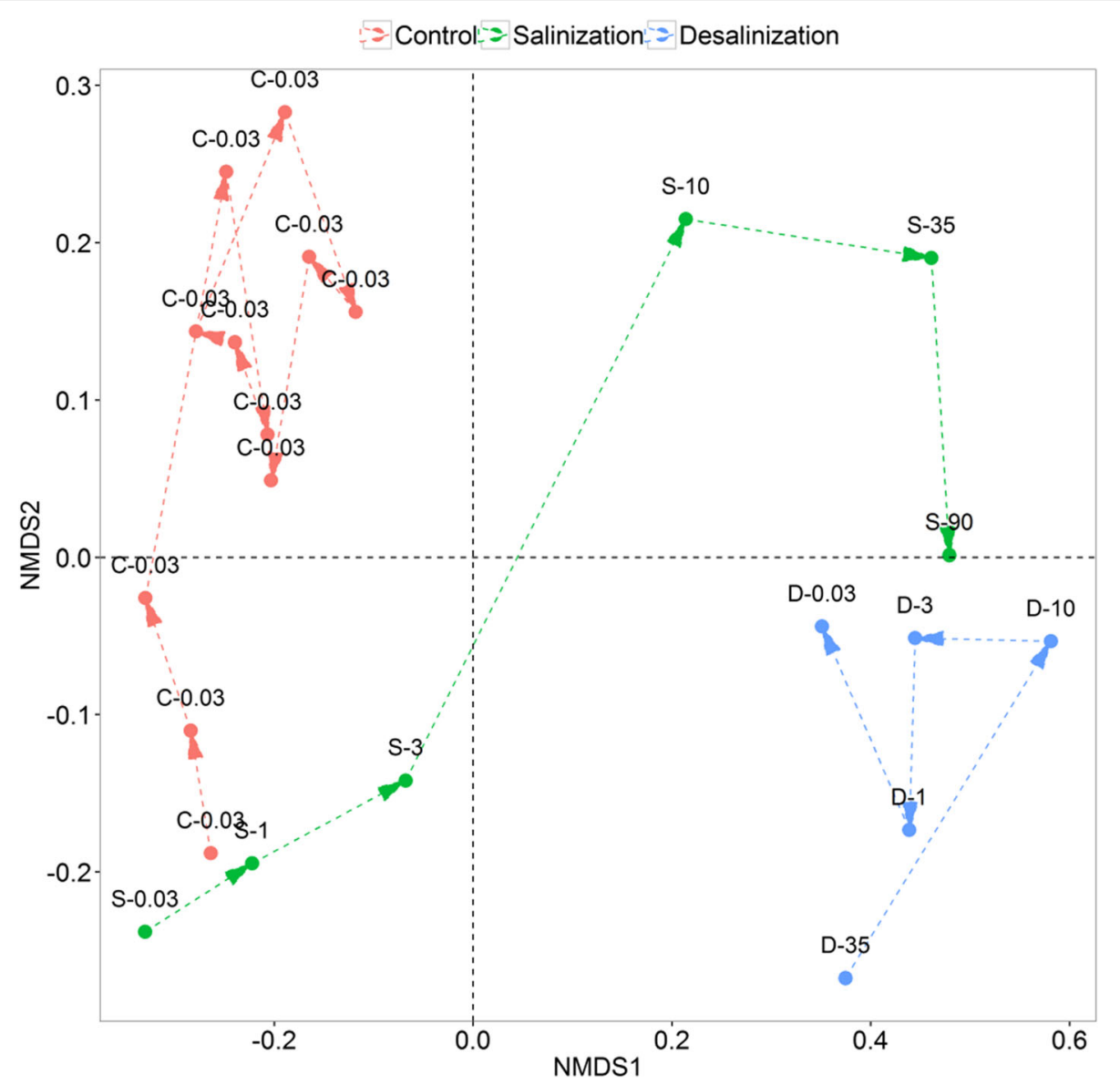

Fig. 4 Phylum-level changes of bacterial community composition during salinization-desalinization cycle. The horizontal axis represents the status of salinity, $\mathbf{S}$ represents salinization, D represents desalinization, and the numbers after each letter represents the salinity in parts per thousand

hypersaline environment from $10 \%$ to $90 \%$, which is in accordance with previous studies [28, 43]. This finding suggests that hypersaline conditions pose ecological barriers to the bacterial communities. Although the vast majority of bacteria have evolved mechanisms to cope with increasing osmolarity, some species will extinct as extracellular osmotic pressure exceeds their tolerance [25]. This is inferred from an acute of loss OTUs during the hypersaline environment. Indeed, according to Wright's species-energy theory, a poorly productive environment leads to less diversity [37, 44, 45]. Previous work has documented that extreme saline environments potentially affect the physiological and biochemical functions of bacterial species [46], resulting in reduced the bacterial primary productivity $[27,43,47]$. As a consequence of this less robust environment, it is expectable that bacterial diversity dramatically decreased at the hypersaline conditions.

The current study details, importantly, that the bacterial communities did not recover to their previous levels after the desalinization-down process. Taxon-specific recovery trajectories varied profoundly, with only Gammaproteobacteria returning to their initial level (Fig 3). Also, the post-disturbance bacterial diversity was not comparable with its original state. Instead, a stable composition formed that was significantly different from the pre-disturbance state. This incomplete recovery is corroborated by previous experimental and observational evidence $[10,17]$. From these key findings we attempt to propose two possible explanations. First, as a reservoir of dormant individuals that are capable of being resuscitated when environmental condition turns favorable, seed bank has been fundamentally used by a wide range of bacterial taxa $[48,49]$. The importance of a seed bank for community recovery from disturbance via the storage effect has been theoretically and empirically demonstrated [50-52]. However, such storage is not unconditional: survival of individual cells in the seed bank is the prerequisite for community recovery [53]. As described above, the bacterial community were exposed to a wide salinity spectrum from $0.03 \%$ to $90 \%$. Actually, the salinity of most water never exceeds $35 \%$ [ [34, 54]. In this regard, most freshwater and oligosaline 


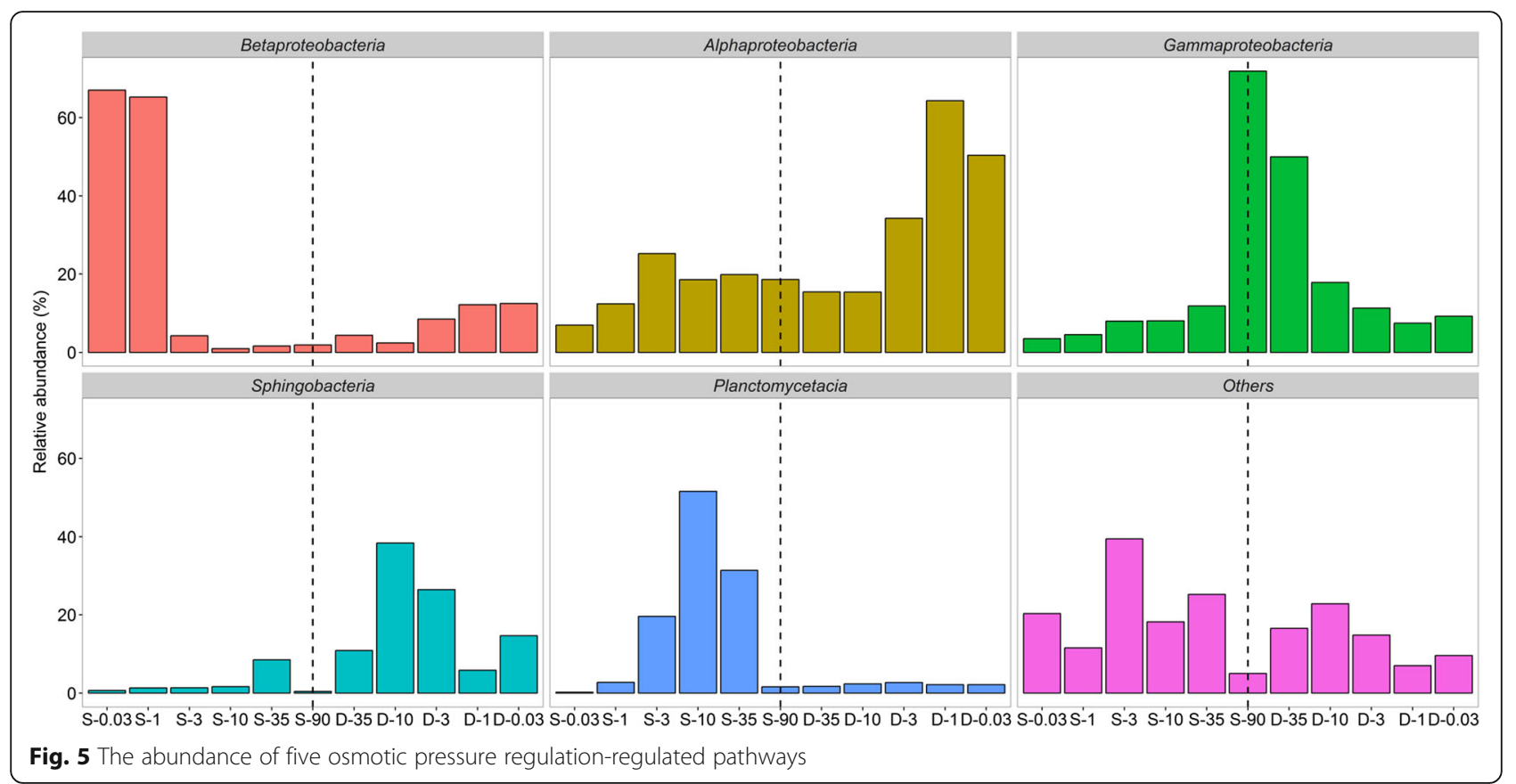

bacterial individuals may not be expected to survive after the extreme $90 \%$. This speculation was confirmed by the fact that almost half of the original OTUs were not detected from desalinization process. Consequently, there is no complete reservoir for the bacterial community to utilize for return to a full, pre-disturbance level. A second explanation is presented for recovery abilities of bacterial communities, namely that dormant organisms must be able to interpret the signals associated with a favorable environment, otherwise they will miss opportunities to resuscitate $[49,55,56]$. According to the PICRUSt, we found that five pathways, all of which operate as osmosensors in the transduction of osmotic pressure signals, were significantly inhibited by the extreme hypersaline condition and failed to recover during desalinization. Thus, it is assumed that the sensory capacity of bacterial communities may be impaired by a hypersaline environment. From this study, PICRUSt provides interesting caveats regarding its utility. For instance, this analytical method is only as good as the database of human systems, but it may not be adequate enough to describe that of environmental ecosystem [57]. As a consequence, more accurate approaches are required in future to provide greater evidence of signal interpretation in bacterial community recovery.

Many studies have suggested that bacterial communities are highly capable of recovery after specific disturbance, such as drying-wetting cycle, warming-cooling cycle and lake mixing $[11,38,58,59]$. Thus, it is important to reconcile the two seemingly contradictory results. Relative to moderate perturbation, it is a familiar ecological phenomenon that extreme disturbance triggers regime shifts in communities: the return of external condition to their former state may not reverse such changes in community composition [60]. For instance, Dethlefsen and Relman found that the composition of the gut microbiota stabilized 2 months after the conclusion of their experienced disturbance, but there were significant alterations from its initial state [10]. Similarly, Lazarevic et al. observed a substantial but incomplete recovery of the salivary bacterial community even 3 weeks after antibiotic treatment [61]. We therefore find it necessary to highlight that any attempt to understand recovery of communities must be placed in the context of disturbance extent, duration and intensity $[6,62]$. Additionally, we also note that variation in observed recovery patterns may be time-scale related. Woodward et al. found that most populations of a stream community returned to their pre-disturbance state in about 3 years, however, some took up to a decade to recover after extreme flood-drought cycle [9]. Thus, it is likely that intervals of 2 weeks' time are too short for a complete recovery.

Our results of this study were obtained from a simplified experimental setup under laboratory condition, leading to several caveats which were gained for future considerations. Firstly, next generation sequencing cannot differentiate between viable and non-viable bacteria. Consequently, it is still unknow how culturable bacteria respond to the salinization-desalinization cycle. Secondly, the recovery of microbial community is not only influenced by abiotic factors, but also by biotic factors [63]. Specifically, microbes live in complicated networks through a multitude of interactions (e.g. competition, 
mutualism and antagonistism) [64], which govern the dynamics of microbial community recovery. However, current study did not reveal how these interactions guide the recovery strategy during the salinization-desalinization cycle. Finally, a set of bacterial communities are linked in natural ecosystem by dispersal of multiple species that are referred to as metacommunities [15]. In this case, the recovery of a bacterial community is controlled by inoculation of individual species from other habitats, such as sediment and air. [22]. The focus of the current research was a single habitat, namely water, so we cannot address the role of exogenous bacterial inoculation on community recovery. Collectively, we view these recognized limitations as an extremely exciting area for future work.

\section{Conclusions}

This study provided insights into the recovery ecology of bacterial communities after an extreme disturbance. Current results showed that an oligosaline environment promotes diversity within the bacterial community, which may be related to a greater niche availability for both halotolerant and halosensitive bacteria at a moderate salinity level. However, a hypersaline environment poses ecological barriers to the bacterial communities, leading to their functional deficit and even annihilation. After desalinizationdown process, the bacterial communities did not recover to their initial states. The possible underlying mechanism may be that the extreme hypersalinity impairs the seed bank of the bacterial community, as well as the capacity of their osmosensors to identify a return to favorable environmental conditions for greater recovery.

\section{Methods}

\section{Experimental set-up}

The mesocosm experiment was conducted from $15 \mathrm{Jul}$. to 1 Dec. 2015 by self-made glass (Fig. 6). Six glass containers (each with a volume of $120 \mathrm{~L}$ ) were divided into two groups (control and treatment) with three replicates in each group. The experimental water was taken from Lake Bosten, the largest inland freshwater lake in China

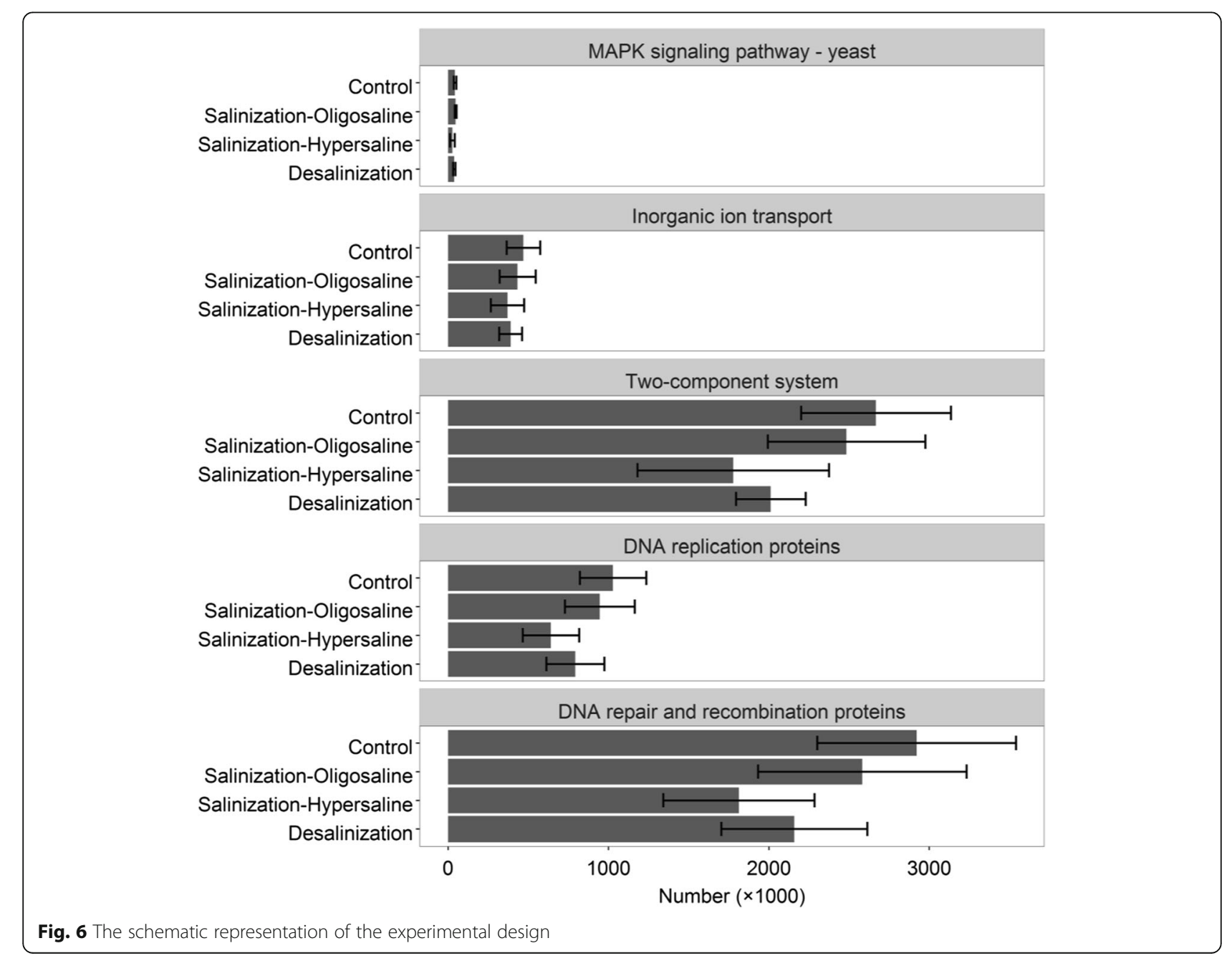


(salinity: $0.03 \%$ ). Before being transferred into each container, the original water was stored in a single tank in a sterile room for 15 days to homogenize and stabilize the bacterial communities [26, 31]. Subsequently, each glass container was simultaneously filled with $100 \mathrm{~L}$ of original water. For the control group, three containers were placed aside without any disturbance for the course of the entire experimental period. The treatment group was designed to experience the extreme salinization-up process, followed by a desalinization-down process. To simulate the salinization, sterile crystallized salt was stepwise added at 15-day intervals to obtain an increasing salinity gradient of $1 \%$, $3 \%$, $10 \%$, $35 \%$, and $90 \%$. To simulate the desalinization, sterilized $\left(120{ }^{\circ} \mathrm{C}\right.$ for $30 \mathrm{~min}$ ) original water was stepwise added to create a symmetric decreasing salinity gradient of $35 \%, 10 \%$, $3 \%$, $1 \%$, and $0.03 \%$ at 15 -day intervals. During the experiment, all incubations were carried out at $26{ }^{\circ} \mathrm{C}$ with caps covering the obtainers in order to prevent airborne bacteria from contaminating the system.

During experimental sampling, all tools were washed by sterile deionized water five times. An initial sample of $600 \mathrm{~mL}$ of water was taken before adding the sterile salt or additional water. For $16 \mathrm{~S}$ rRNA genetic analysis, a subsample $(400 \mathrm{~mL})$ of water was immediately filtered on $0.22 \mu \mathrm{m}$ pore size polycarbonate filters by a hand-driven vacuum pump. The filters were stored at $-80{ }^{\circ} \mathrm{C}$ before extraction of nucleic acids. The remaining water $(200 \mathrm{~mL})$ was transported to the laboratory for chemical analysis. Chemical analyses including total nitrogen (TN), total phosphorus (TP), and dissolved organic carbon (DOC), were performed according to standard methods [65]. During sampling, the physical properties including dissolved oxygen, salinity, temperature, and $\mathrm{pH}$ were determined by a multiparameter water quality sonde (YSI 6600 V2, USA).

\section{DNA extraction, PCR amplification, and sequencing} Total DNA was extracted using a FastDNA spin kit for soil (MP Bio-medical, Carlsbad, CA) according to the manufacturer's instructions [66]. To amplify the V5-V6 hypervariable regions of $16 \mathrm{~S}$ rRNA genes, the universal primers 789F (5'- TAGATACCCSSGTAGTCC-3') and 1068R (5'-CTGACGRCRGCCATGC -3') were used. The polymerase chain reaction (PCR) was performed in $50 \mu \mathrm{L}$ reaction mixture containing $5 \mu \mathrm{L}$ of $10 \times$ PCR buffer, $4 \mu \mathrm{L}$ of $\mathrm{MgCl}_{2}(25 \mathrm{mM}), 3 \mu \mathrm{L}$ of deoxynucleotide triphosphates (dNTPs, $2.5 \mathrm{mM}$ each), $1 \mu \mathrm{L}$ of each primer $(10 \mu \mathrm{M}), 30 \mathrm{ng}$ template DNA, and $0.3 \mu \mathrm{L}$ of Taq polymerase $(5 \mathrm{U} \mu \mathrm{L}-1$ Fermentas). PCR cycling was carried out in a thermocycler (Applied Biosystems Veriti Thermal Cycler) using a touchdown program: denaturation at $94{ }^{\circ} \mathrm{C}$ for $5 \mathrm{~min}, 11$ cycles of denaturation at $94{ }^{\circ} \mathrm{C}$ for $1 \mathrm{~min}$, annealing at $65{ }^{\circ} \mathrm{C}$ for $1 \mathrm{~min}$, and extension at
$72{ }^{\circ} \mathrm{C}$ for $1 \mathrm{~min}$. Nineteen additional cycles were carried out at an annealing temperature of $55{ }^{\circ} \mathrm{C}$, followed by a final extension at $72{ }^{\circ} \mathrm{C}$ for $10 \mathrm{~min}$.

The pair-end sequencing was performed on an Illumina Miseq platform. Unique barcodes were added to each sample. The paired reads from each sample were initially merged with a minimum overlap of 100 and 8 maximum mismatches allowed in the overlap region. Primers and barcodes were trimmed so that the average Phred quality score for each read was above 20. After trimming, these reads were assembled by FLASH (https://github.com/dstreett/FLASH2). Only those reads with consecutive and identical bases, and without ambiguous bases, were used for further analysis. Chimera sequences were identified and removed using UCHIME [67]. The software QIIME was used to cluster the high-quality sequences into operational taxonomic units (OTUs) with a 0.03 cut-off value (equivalent to $97 \%$ similarity) [68]. The longest sequence in each cluster was chosen to be the representative sequence, which was annotated according to the SILVA database.

\section{Predictive metagenome analysis}

We used the Phylogenetic Investigation of Communities by Reconstruction of Unobserved States (PICRUSt) software package (version 1.0.0, http://picrust.github.io/ picrust/) to predict the metagenome functional content from the 16S rRNA dataset [57]. PICRUSt-compatible OTU tables were constructed using the closed-reference OTU picking protocol in QIIME against Greengenes by using the function 'pick_reference_otus_through_otu_table.py'. The nearest sequenced taxon index was developed as a measure to describe the novelty of bacteria within an OTU table, with respect to previous sequenced genomes. The obtained OTU table was normalized to reflect their true abundance, and then predict_metagemones.py with default settings was applied to gain the predicted metagenomics table with Kyoto Encyclopedia of Genes and Genomes (KEGG) hierarchy collapse at level 3.

\section{Statistical analysis}

All statistical analyses and visualization were carried out using vegan, betapart, and ggplot 2 packages in the $\mathrm{R}$ environment (version 3.2.2, http://www.r-project.org). Before alpha diversity analysis, the $16 \mathrm{~S}$ rRNA data from individual sample were rarefied to 69,899 reads (the minimal read number across all samples). Faith's phylogenetic diversity (PD) [69] and rarefied richness were calculated in QIIME. Shannon diversity was determined by diversity function. Pielou's Evenness, $J$, was calculated based on Shannon diversity, $\mathrm{H}(J=\mathrm{H} / \log$ (richness)). The two-sided $t$-test was applied to determine if the 
$\alpha$-diversity in different groups were significantly different from each other.

Prior to beta diversity analysis, all OTU abundance data were Hellinger-transformated [70]. Non-metric multidimensional scaling analysis (NMDS) was conducted with Bray-Curtis distance as well as (un)weighted UniFrac distance through the metaMDS function. The Bray-Curtis distance matrix was calculated by the vegdist function, and the (un)weighted UniFrac distance was calculated through QIIME. In order to access the variation of bacterial community, Sørensen dissimilarity matrix was determined using beta.multi function [71]. Additionally, we also performed a nested permutational multivariate analysis of variance (PERMANOVA, [72]) based on Bray-Curtis similarity using adonis function to test if the bacterial community composition in distinct groups were significantly different from each other.

Taxonomic and trait compositions were first assessed by computing Bray-Curtis distance between consecutive sampling dates across the entire duration of the study in order to detect major changes in community composition (i.e. more dissimilar values corresponding to higher distances).

\section{Additional files}

Additional file 1: Table S1. The environmental properties of control and treatment groups. (DOCX $17 \mathrm{~kb}$ )

Additional file 2: Figure S1. The rarefaction plot indicating community observed OTUs based on 165 rRNA gene sequences. C1-C11 presents the control groups; S1-S6 presents the salinization groups, in which the salinity is $0.03 \%, 1 \%$, $3 \%$, $10 \%$, $35 \%$, and $90 \%$, respectively; D1-D5 presents the desalinization groups, in which the salinity is $35 \%$, $10 \%$, $3 \%$, $1 \%$, and $0.03 \%$, respectively. (DOCX $306 \mathrm{~kb}$ )

Additional file 3: Figure S2. Non-metric multidimensional scaling ordination of bacterial communities in salinization-desalinization cycle and control groups based on unweighted and weighted Unifrac distance (DOCX $113 \mathrm{~kb}$ )

Additional file 4: Figure S3. Phylum-level changes of bacterial community composition during the control group (DOCX $224 \mathrm{~kb}$ )

Additional file 5: Table S2. The value of the nearest sequenced taxon index (NSTI) for each sample calculated by PICRUSt (DOCX $16 \mathrm{~kb}$ )

\section{Abbreviations}

DOC: Dissolved organic carbon; KEGG: Kyoto Encyclopedia of Genes and Genomes; NMDS: Non-metric multidimensional scaling analysis; NSTI: Nearest sequenced taxon index; OTU: Operational Taxonomic Units; PCR: Polymerase chain reaction; PD: Faith's phylogenetic diversity; PERMANOVA: Permutational Multivariate Analysis of Variance; PICRUSt: Phylogenetic Investigation of Communities by Reconstruction of Unobserved States; TN: Total nitrogen; TP: Total phosphorus

\section{Acknowledgements}

We thank staff at the Environmental Monitoring Station of the Environmental Protection Bureau of Bayingolin Mongolia Autonomous Prefecture for helping with sample collection and water chemical analysis.

\section{Funding}

This design of this study was supported by the National Water Pollution Control and Management of Science and Technology Major Projects (grant 2013ZX07004), the National Natural Science Foundation of China (Grant No. 41171388, 41471040, 41501101). These funds also provided a lot of support in collection, interpretation of data, as well as the writing.

\section{Availability of data and materials}

All data generated or analyzed during current study are available from the corresponding author on reasonable request.

\section{Authors' contributions}

YH and GG conceived and designed the experiments. JC and CB performed sample collection and analyzed the data; $\mathrm{YH}, \mathrm{KS}$, and XT wrote the paper. All authors have read and approved the manuscript.

Ethics approval and consent to participate

Not applicable.

\section{Consent for publication}

Not applicable.

\section{Competing interests}

The authors declare that they have no competing interests.

\section{Publisher's Note}

Springer Nature remains neutral with regard to jurisdictional claims in published maps and institutional affiliations.

\section{Author details}

'State Key Laboratory of Lake Science and Environment, Nanjing Institute of Geography and Limnology, Chinese Academy of Sciences, 73 East Beijing Road, Nanjing 210008, China. ${ }^{2}$ University of Chinese Academy of Sciences, Beijing 100000, China.

Received: 28 June 2018 Accepted: 31 October 2018

Published online: 23 November 2018

References

1. Sousa WP. The role of disturbance in natural communities. Annu Rev Ecol Syst. 1984;15(15):353-91.

2. Plante CJ. Defining disturbance for microbial ecology microbial ecology Microb Ecol. 2017;74(2):259-63.

3. Holling CS. Resilience and stability of ecological systems. Annu Rev Ecol Evol Syst. 1973:4(2):1-23.

4. Pimm SL. The complexity and stability of ecosystems. Nature. 1984; 307(5949):321-6.

5. Landres PB, Morgan P, Swanson FJ. Overview of the use of natural variability concepts in managing ecological systems. Ecol Appl. 1999:9(4):1179-88.

6. Fraterrigo JM, Rusak JA. Disturbance-driven changes in the variablity of ecological patterns and process. Ecol Lett. 2008;11(7):756-70.

7. Hao YQ, Zhao XF, Zhang DY. Field experimental evidence that stochastic processes prodominate in the initial assembly of bacterial communities. Environ Microbiol. 2016;18(6):1730-9.

8. Kreyling J, Jentsch A, Beierkuhnlein C. Stochastic trajectories of succession initiated by extreme climatic events. Ecol Lett. 2011;14(8):758-64.

9. Woodward G, Bonoada N, Feeley HB, Giller P. Resilience of a stream community to extreme climatic events and long-term recovery from a catastrophic flood. Freshw Biol. 2015;60(12):2497-510.

10. Dethlefsen $L$, Relman DA. Incomplete recovery and individualized responses of the human distal gut microbiota to repeated antibiotic perturbation. Proc Natl Acad Sci U S A. 2011;1(11):4554-61.

11. Shade A, Read JS, Welkie DG, Kratz TK, Wu CH, McMahon KD. Resistance, resilence and recovery: aquatic bacterial dynamics after water column disturbance. Environ Microbiol. 2011:13(10):2752-67.

12. Cotner JB, Biddanda BA. Small players, large role: microbial influence on biogeochemical processes in pelagic aquatic ecosystems. Ecosystems. 2002; 5(2):105-21

13. Azam F, Malfatti F. Microbial structuring of marine ecosystems. Nat Rev Microbiol. 2007;5(10):782-91.

14. Chase JM. Community assembly: when should history matter? Oecologia. 2003;136(4):489-98. 
15. Leibold MA, Holyoak M, Mouquet N, Amarasekare P, Chase JM, Hoopes MF, Holt RD, Shurin JB, Law R, Tilman D, et al. The metacommunity concept:a framword for multi-scale community ecology. Ecol Lett. 2004;7(7):601-13.

16. Li HB, Xing $P, W u Q L$. The high resilience of the bacterioplankton community in the face of a catastrophic disturbance by a heavy Microcystis bloom. FEMS Microbiol Ecol. 2012;82(1):192-201.

17. Shao K, Gao G, Tang X, Wang Y, Zhang L, Qin B. Low resilience of the particle-attached bacterial community in response to frequent wind-wave disturbance in freshwater mesocosms. Microbes Environ. 2013;28(4):450-6.

18. Fierer N, Lennon JT. The generation and maintenance of diversity in microbial communities. Am J Bot. 2011;98(3):439-48.

19. Hubbell SP, Borda-de-Água $L$. The united neutral theory of iodiversity and biogeography: reply. Ecology. 2004;85(11):3175-8.

20. Martiny JBH, Bohannan BJM, Brown JH, Colwell RK, Fuhrman JA, Green JL, Horner-Devine MC, Kane M, Krumins JA, Kuske CR, et al. Microbial biogeography: putting microoganisms on the map. Nat Rev Microbiol. 2006; 4(2):102-12.

21. Schaefer $V$. Alien invasions,ecological restoration in cities and the loss of ecological memory. Restor Ecol. 2009;17(2):171-6.

22. Ruiz-González C, Niño-García JP, PAd G. Terrestrial origin of bacterial communities in complex boreal freshwater networks. Ecol Lett. 2015; 18(11):1198-206.

23. Nemergut DR, Costello EK, Hamady M, Lozupone C, Jiang L, Schmidt SK, Fierer N, Townsend AR, Cleveland CC, Stanis L, et al. Global patterns in the biogeography of bacterial taxa. Environ Microbiol. 2011;13(1):135-44.

24. Lozupone CA, Knight R. Global pattern of bacterial diversity. Proc Natl Acad Sci U S A. 2011;104(27):11436-40.

25. Roelßer M, Müller V. Osmoadaptation in bacteria and archaea:common principles and differences. Environ Microbiol. 2001;3(12):743-54.

26. Yan N, Marschner P. Response of microbial activity and biomass to increasing salinity depends on the final salinity. not the orignal salinity Soil Biol Biochem. 2012;53:50-5.

27. Cortés-Lorenzo C, Rodríguez-Díaz M, Sipkema D, Juárez-Jiménez B, Rodelas B, Smidt H, González-López J. Effect of salinity on nitrification efficiency and structure of ammonia-oxidizing bacterial communities in a submerged fixed bed bioreactor. Chem Eng J. 2015;266(6):233-40.

28. Pedrós-Alio C, I Calderón-Paz J, H.MacLean M, Medina G, Marrasé C, Gasol JM, Guixa-Boixereu N. The microbial food web along salinity gradients. FEMS Microbiol Ecol. 2000;32(2):143-55.

29. Edmonds JW, Weston NB, Joye SB, Mou X, Moran MA. Microbial community response to seawater amendment in low-salinity tidal sediments. Microb Ecol. 2009;58(3):558-68.

30. Yang J, Ma LA, Jiang HC, Wu G, Dong HL. Salinity shapes microbial diversity and community structure in surface sediments of the Qinghai-Tibetan lakes. Sci Rep. 2016;6:25078.

31. Zhang L, Gao G, Tang X, Shao K. Can the freshwater bacterial communities shift to the "marine-like" taxa? J Basic Microbiol. 2013;54(11):1264-72.

32. Tang XM, Xie GJ, Shao KQ, Sai-Bayartu, Chen YG, Gao G. influence of salinity on the bacterial communitiy composition in Lake Bosten,a large oligosaline Lake in arid northwestern China. Appl Environ Microbiol 2012;78(134):4748-4751.

33. Rousk J, K.Elyaagubi F, L.Jones D, L.Godbold D. Bacterial salt tolerance is unrelated to soil salinity across an arid agroecosystem salinity gradient. Soil Biol Biochem. 2011;43(9):1881-7.

34. Herlemann DPR, Labrenz M, Jurgens K, Bertilsson S, Waniek JJ, Andersson AF. Transitions in bacterial communities along the $2000 \mathrm{~km}$ salinity gradient of the Baltic Sea. ISME J. 2011;5(10):1571-9.

35. Ladányi Z, Blanka V, Deák ÁJ, Rakonczai J, Mezösi G. Assessment of soil and vegetation changes due to hydrologically driven desalinization process in an alkaline wetland. Hungary Ecol Complex. 2016;25:1-10.

36. Wang J, Yang D, Zhang Y, Shen J, Cvd G, Hahn MW, Wu Q. Do patterns of bacterial diversity along salinity gradients differ from those observed for macroorganisms? PLoS One. 2011;6(11):e27597.

37. Bosker T, Santoro G, Melvin SD. Salinity and sensitivity to endocrine disrupting chemicals: a comparison of reproductive endpoints in small-bodied fish exposed under different salinities. Chemosphere. 2017:183:186-96.

38. Shade A, Read JS, Youngblut ND, Fierer N, Knight R, Kratz TK, Lottig NR, Roden EE, Stanley EH, Stombaugh J, et al. Lake microbial communities are resilitent after a whole-ecosystem disturbance. ISME J. 2012;6(12):2153-67.
39. Katz RW, Brown BG. Extreme events in a changing climate: variability is more important than averages. Clim Chang. 1992;21(3):289-302.

40. McCann KS. The diversity-stability debate. Nature. 2000;405(6783):228-33.

41. Williams WD, Boulton AJ, Taaffe RG. Salinity as a determinant of salt lake fauna: a question of scale. Hydrobiologia. 1990;197(1):257-66.

42. Hammer UT, Heseltine M. Aquatic macrophytes in saline lakes of the Canadian praires. Hydrobiologia. 1988;44:101-16.

43. Yannarell AC, Steppe TF, Paerl HW. Disturbance and recovery of microbial community structure and function following hurricane Frances. Environ Microbiol. 2007;9(3):576-83.

44. Horner-Devine MC, Leibold MA, Smith VH, Bohannan BJM. Bacterial diversity patterns along a gradient of primary productivity. Ecol Lett. 2003;6(7):613-22

45. Wright $\mathrm{DH}$. Species-energy theory: an extension of species-area theory. Oikos. 1983;41(3):496-506

46. Sun W, Zhao HL, Wang F, Liu YF, Yang J, Ji M. Effect of salinity on nitrogen and phosphorus removal pathways in a hydroponic micro-ecosystem planted with Lythrum Salicaria L. Ecol Eng. 2017;105:205-10.

47. Moussa MS, Sumanasekera DU, Irahim SH, Lubberding HJ, Hooijmans CM, Gijzen HJ. Van-Loosdrecht MCM. Long term effects of salt on activity, population structure and floc characteristics in enriched bacterial cultures of nitrifiers. Water Res. 2006;40(7):1377-88.

48. Jones SE, Lennon JT. Dormancy contributes to the maintenance of microbial diversity. Proc Natl Acad Sci U S A. 2010;107(3):5881-6.

49. Lennon JT, Jones SE. Microbial seed banks: the ecological and evolutionary implications of dormany. Nat Rev Microbiol. 2011;9(2):119-30.

50. Lamarre C, Sokol S, Debeaupuis J-P, Henry C, Lacroix C, Glaser P, Coppée J$Y$, Francois J-M, Latgé J-P. Transcriptomic analysis of the exit from dormancy of aspergillus fumigatus conidia. BMC Genomcis. 2008;9(1):417.

51. Kalamees $R$, Zobel $M$. The role of the seed bank in gap regeneration in a calcareous grassland community. Ecology. 2008;83(4):1017-25.

52. Cole JJ. Aquatic microbiology for ecosystems scientists: new and recycled paradigms in ecological microbiology. Ecosystems. 1999;2(3):215-25.

53. Shade A, Peter $H$, Allison SD, Baho DL, Berga M, Bürgmann $H$, Huber DH, Langenheder S, Lennon JT, Martiny JBH, Matulich KL, Schmidt TM, Handelsman J. Fundamentals of microbial community resistance and resilience. Front Microbiol. 2012;3(3):417.

54. Morse JW, Mucci A, Millero FJ. The solubility of calcite and aragonite in seawater of $35 \%$. Salinity at $25^{\circ} \mathrm{C}$ and atmospheric pressure. Geochim Cosmochim Acta. 1980:44(1):85-94.

55. Rees M. Evolutionary ecology of seed dormancy and seed size. Phil Trans R Soc B. 1996;351(1345):1299-308.

56. Soula B, Menu F. Variability in diapause duration in the chestnut weevil: mixed ESS, genetic polymorphism or bet-hedging? Oikos. 2003;100:574-80.

57. Langille MGI, Zaneveld J, Caporaso JG, McDonald D, Knights D, Reyes JA, Clemente JC, Burkepile DE, Thurber RLV, Knight R, et al. Predictive functinal profiling of microbial communities using 165 rRNA marker gene sequences. Nat Biotechnol. 2013;31(9):814-21.

58. Zhou X, Fornara D, Ikenaga M, Akagi I, Zhang $R$, Jia Z. The resilience of microbial community under drying and rewetting cycles of three forest soils. Front Microbiol. 2016;7:1101.

59. Rui JP, Li JB, Wang SP, An JX, W-t L, Lin QY, Yang YF, He ZL, Li XZ. Responses of bacterial communities to simulated climate changes in alpine meadow soil of the Qinghai-Tibet plateau. Appl Environ Microbiol. 2015; 81(17):6070-7.

60. Scheffer M, Carpenter SR. Catastrophic regime shifts in ecosystems: linking theory to observation. Trends Ecol Evol. 2003;18(12):648-56.

61. Lazarevic V, Manzano S, Gaïa N, Girard M, Whiteson K, Hibbs J, Francois P, Gervaix A, Schrenzel J. Effects of amoxicillin treatment on the salivary microbiota in children with acute otitis media. Clin Microbiol Infect. 2013; 19(8):335-42.

62. Singer A, Johst K. Transience after disturbance: obligate species recovery dynamics depend on disturbance duration. Theor Popul Biol. 2017;115:81-8.

63. Gray DK, Arnott SE, Shead JA, Derry AM. The recovery of acid-damaged zooplankton communities in Canadian Lakes: the relative importance of abiotic, biotic and spatial variables. Freshw Biol. 2012;57:741-58.

64. Faust $K$, Raes J. Microbial interactions: from networks to models. Nat Rev Microbiol. 2012;10(8):538-50.

65. Jin XC, Tu QY: The standard methods for observation and analysis of lake eutrophication: China environmental science process, Beijing; 1990. 
66. Zhou J, Bruns MA, Tiedje JM. DNA recovery from soils of diverse composition. Appl Environ Microbiol. 1996;62(2):316-22.

67. Edgar R, Haas B, Clemente J, Quince C. Knight R. UCHIME imporves sensitivity and speed of chimera detection. Bioinformatics. 2011;27(16): 2194-200.

68. Caporaso J, Kuczynski J, Stombaugh J, Bittinger K, Bushman F, Costello E, Fierer N, Peña A, Goodrich J, Gordon J, et al. Qiime allows analysis of highthroughtput community sequencing data. Nat Methods. 2010;7(5):335-6.

69. Faith DP. Conservation evaluation and phylogenetic diversity. Biol Conserv. 1992;61(1):1-10.

70. Legenre P, Gallagher ED. Ecologically meaningful transformations for ordination of species data. Oecologia. 2001;129(12):271-80.

71. Baselga A. Orme CDL. Betapart: an R package for the study of beta diversity. Methods Ecol Evol. 2012;3:808-12.

72. Anderson MJ. Permutational multivariate analysis of variance. Available: https://doi.org/10.1111/j.1442-9993.2001.01070.pp.X.

Ready to submit your research? Choose BMC and benefit from:

- fast, convenient online submission

- thorough peer review by experienced researchers in your field

- rapid publication on acceptance

- support for research data, including large and complex data types

- gold Open Access which fosters wider collaboration and increased citations

- maximum visibility for your research: over $100 \mathrm{M}$ website views per year

At $\mathrm{BMC}$, research is always in progress.

Learn more biomedcentral.com/submissions 